Letter to the Editor

\title{
Oncocytoma: risk of promoting unnecessary surgery
}

\author{
Hannah Warren ${ }^{1}$, Joana B. Neves ${ }^{2,3}$, Maxine G. B. Tran ${ }^{2,3}$
}

Corresponding author: m.tran@ucl.ac.uk

\section{Affiliations}

\section{Department of Urology, King's College Hospital NHS Foundation Trust}

\section{Division of Surgery and Interventional Science, University College London, UK}

\section{Specialist Centre for Kidney Cancer, Royal Free London NHS Foundation Trust}

Re : Maegher, Lane, Capitanio et al. Comparison of renal functional outcomes of active surveillance and partial nephrectomy in the management of oncocytoma. World Jounal of Urology 2020

We read with interest the article by Meagher et al. on functional outcomes for patients undergoing active surveillance (AS) versus partial nephrectomy for renal oncocytoma(1). We commend the initiative to assess long-term outcomes in patients avoiding surgery for biopsy-proven benign disease, however respectfully disagree with the authors' conclusion 'that benign lesions may have a significant impact on kidney function'. Rather, the study exemplifies the caution that must be taken in mistaking association for causality in non-randomised studies.

The observational nature of this study introduces selection bias between treatment groups that threatens the validity of any comparison. Our main concern, that has not been addressed in this study, is the reason patients were selected for AS over upfront partial nephrectomy. Factors likely to play a role in decision making include co-morbidity profile, fitness, smoking and economic status in insurance-based healthcare settings. These are known risk factors for development of chronic kidney disease $(C K D)(2,3)$. We suspect that these elements that precluded surgery are the underlying reasons for eGFR decline rather than the natural history of oncocytoma. While we concede that the authors demonstrate age, prevalence of hypertension and diabetes was similar in both groups, one cannot correct for all known and unknown variables in this study design. We noted previously in a propensity scorematched analysis using population-based data, even extensive matching including but not limited to Charlson comorbidity index, cardiovascular disease, hypertension, diabetes, and socioeconomic status, was not able to adequately account for unknown confounding factors contributing to non-cancer survival differences in patients with pT1a kidney tumours managed with AS $(4,5)$.

The authors' subanalysis showed that patients on AS who developed de novo CKD had a lower baseline eGFR than those who did not, supporting the notion these 
patients were at a higher baseline risk(3) regardless of management for their oncocytoma. The additional risk factor profile of this subgroup was not reported or discussed.

Oncocytoma represents $12 \%$ of $\mathrm{T} 1$ renal masses(6), and there is increasing concern that surgical resection as default management represents overtreatment of this benign pathology. Surgery is not without risk. Meagher et al reports $20 \%$ overall surgical complication rate, with major complications (Clavien III-IV) at $4.5 \%$. This is in line with our previous population-based analysis on the complication rates for the surgical treatment of oncocytomas(7). Lui et al. have reported outcomes for 53 biopsy-proven oncocytomas followed safely with AS over a median follow up of 34 months(8). Only six (11\%) patients proceeded to surgical excision or ablation during follow up; due to large size, rapid growth ( $>5 \mathrm{~mm} / \mathrm{annum}$ ) or flank pain.

While the authors' suggestion of a toxic peri-tumour microenvironment causing damage to surrounding nephrons is hypothesis generating, care must be taken in drawing stronger causal conclusions. Interpreting these findings as an indication for surgery to 'optimize functional preservation' in oncocytoma without more robust data is misleading. While we agree that biopsy-proven oncocytoma is not a blanket contraindication to surgery, surgical risk and distribution of health resource must be considered against treatment of asymptomatic, benign disease.

Acknowledgements: JBN is funded by a Medical Research Council (MRC) Clinical Research Training Fellowship

1. Meagher MF, Lane BR, Capitanio U, Mehrazin R, Bradshaw AW, Noyes S, et al. Comparison of renal functional outcomes of active surveillance and partial nephrectomy in the management of oncocytoma. World J Urol [Internet]. 2020; Available from: https://doi.org/10.1007/s00345-020-03299-5

2. $\quad$ Lash JP, Go AS, Appel LJ, He J, Ojo A, Rahman M, et al. Chronic renal insufficiency cohort (CRIC) study: Baseline characteristics and associations with kidney function. Clin J Am Soc Nephrol. 2009;4(8):1302-11.

3. Yang W, Xie D, Anderson AH, Joffe MM, Greene T, Teal V, et al. Association of kidney disease outcomes with risk Factors for CKD: Findings from the Chronic Renal Insufficiency Cohort (CRIC) study. Am J Kidney Dis [Internet]. 2014;63(2):236-43. Available from: http://dx.doi.org/10.1053/j.ajkd.2013.08.028

4. Xing M, Kokabi N, Zhang D, Ludwig JM, Kim HS. Comparative effectiveness of thermal ablation, surgical resection, and active surveillance for $\mathrm{T} 1 \mathrm{a}$ renal cell carcinoma: A surveillance, epidemiology, and end results (SEER)-Medicarelinked population study. Radiology. 2018;288(1):81-90.

5. Neves J, Rodrigues F, Tran M. Management of small renal masses. Radiology. 2018;289(1):272-3.

6. Lane BR, Babineau D, Kattan MW, Novick AC, Gill IS, Zhou M, et al. A Preoperative Prognostic Nomogram for Solid Enhancing Renal Tumors $7 \mathrm{~cm}$ or Less Amenable to Partial Nephrectomy. J Urol. 2007;178(2):429-34.

7. Neves JB, Withington J, Fowler S, Patki P, Barod R, Mumtaz F, et al. Contemporary surgical management of renal oncocytoma: a nation's outcome. BJU Int. 2018;121(6):893-9. 
8. Liu S, Lee S, Rashid P, Bangash H, Hamid A, Lau J, et al. Active surveillance is suitable for intermediate term follow-up of renal oncocytoma diagnosed by percutaneous core biopsy. BJU Int. 2016;118:30-4.

\section{Declarations}

Funding: N/A

Conflicts of Interest: The authors have no conflicts of interest to declare Availability of data and material: N/A

Ethics approval: N/A 